\title{
A QUANTITATIVE RELATIONSHIP BETWEEN THE WATER CONTENT OF SKIN AND INFLAMMATION PRODUCED BY CHEMICAL IRRITANTS ${ }^{1}$
}

\author{
By H. VINIK WEISS,2 VINTON E. SILER, AND PETER R. BUECHLER
}

(From the Department of Surgery, College of Medicine, University of Cincinnati, and the Surgical Chemical Laboratory, Cincinnati General Hospital, Cincinnati, O.)

(Submitted for publication April 20, 1951 ; accepted September 10, 1951)

Frequently it is desirable to determine quantitatively the inflammatory response of tissues to chemical irritants. Until now the approach to this problem has depended chiefly upon subjective analysis of the degree of redness or swelling of inflamed tissues, such as that reported by Munch (1). Technics which depend to a considerable extent upon the investigator's visual evaluation possess certain recognized inherent errors. Even the unintentional bias of the investigator may significantly influence the assignment of a specific value to a visually observed physiological phenomenon.

Oettel (2) has described a method of accurately determining the redness associated with inflamed tissue. However, a quantitative relationship between redness and inflammation has not been firmly established. More recently Weatherby (3) has utilized the phenomenon of trypan blue fixation at sites of inflammation. The color depth of the trypan blue deposited in inflamed sites is visually compared with color standards, and a quantitative relationship between trypan blue fixation and inflammation has been found to exist over a limited range. This technic appears to be extremely sensitive to hydrogen ion concentration and is not entirely satisfactory for irritants which produce tissue destruction.

To obviate completely subjective analysis, a new basis for determining the degree of inflammation was sought. It is generally agreed that a fundamental change in inflammatory processes is manifested by increased capillary permeability and passage of fluid into the injured area. The following study was conducted to determine whether the fluid content of an area is proportional to the intensity of inflammation. If this relationship ex-

\footnotetext{
1 This study was aided by a grant from the Ethicon Suture Laboratories, Inc.

2 Ethicon Fellow, University of Cincinnati.
}

ists, a measurement of the water content by totally objective procedures should afford a potential method of determining quantitatively the response of tissue to chemical irritants.

\section{EXPERIMENTAL METHOD}

Hair from the ventral surface of five-pound white male rabbits was removed with electrical clippers (Oster model A-2 animal clipper with No. 40 cutting head). The skin was thoroughly cleansed with a dilute solution of tincture of green soap and rinsed with distilled water. Selected sites were injected intradermally using syringes of $0.25 \mathrm{ml}$. capacity and hypodermic needles of 25 to 27 gauge. Injections were of $0.05 \mathrm{ml}$. amounts. Rabbits were sacrificed 24 hours after injection. An area one inch square surrounding the injected site was marked in ink and lightly scored with a scalpel to facilitate accurate excision. After all areas had been demarcated, the dermis layer was cleanly separated from the underlying subcutaneous tissue and transferred to weighing bottles which had been previously weighed. The weight of the wet tissue was determined. The samples were then heated under 28 to 29 inches of vacuum in an oven at $70^{\circ} \mathrm{C}$. for 18 hours. The samples were cooled and reweighed to obtain the weight of dry tissue and to determine the quantity of water present in the initial specimen. A factor to be designated as $W$ was computed.

$$
W=\frac{\text { Weight of water (g.) }}{\text { Weight of dry tissue (g.) }} \times 100 .
$$

The effect of three irritants, $360 \mathrm{E}$, Sovasol 35, and hydrochloric acid, was studied by this procedure. Both $360 \mathrm{E}$ and Sovasol 35 are non-polar materials which have been employed in the sterilization of catgut sutures and were found by the usual technic to possess potent inflammatory properties. Both fractions have a specific gravity of 0.75 and are water insoluble; however, up to 2 per cent emulsions may be uniformly dispersed in isotonic saline which contains two drops of Aquet $/ 100 \mathrm{ml}$. (Aquet is a commercial non-ionic surface active agent.)

A stock solution containing two drops of Aquet/100 $\mathrm{ml}$. of isotonic saline was prepared. Concentrations of $0.5,0.75,1.0,1.5$, and 2.0 per cent of $360 \mathrm{E}$ and Sovasol 35 were prepared by volume in the stock solution.

Six rabbits were used to test each irritant. Six sites were injected in each rabbit, one with the control solu- 
TABLE I

$\mathrm{W}$ and per cent change in $\mathrm{W}$

Rabbits 9930 and 9931

Injected with different concentrations of $360 \mathrm{E}$

\begin{tabular}{|c|c|c|c|c|c|c|c|c|c|c|c|}
\hline \multirow{3}{*}{ Rabbit } & \multirow{3}{*}{ Control } & \multicolumn{10}{|c|}{ Concentration $360 \mathrm{E}$ (by volume) } \\
\hline & & \multicolumn{2}{|c|}{0.5 per cent } & \multicolumn{2}{|c|}{0.75 per cent } & \multicolumn{2}{|c|}{1.0 per cent } & \multicolumn{2}{|c|}{1.5 per cent } & \multicolumn{2}{|c|}{2.0 per cent } \\
\hline & & $\boldsymbol{W}$ & $\Delta W(\%)$ & $W$ & $\Delta W(\%)$ & $\boldsymbol{W}$ & $\Delta W(\%)$ & $W$ & $\Delta W(\%)$ & $W$ & $\Delta W(\%)$ \\
\hline $\begin{array}{l}9930 \\
9931\end{array}$ & $\begin{array}{l}233 \\
123\end{array}$ & $\begin{array}{l}333 \\
177\end{array}$ & $\begin{array}{l}42.8 \\
43.9\end{array}$ & $\begin{array}{l}328 \\
212\end{array}$ & $\begin{array}{l}40.7 \\
72.3\end{array}$ & $\begin{array}{l}424 \\
237\end{array}$ & $\begin{array}{l}82.1 \\
92.7\end{array}$ & $\begin{array}{l}429 \\
233\end{array}$ & $\begin{array}{l}84.2 \\
89.4\end{array}$ & $\begin{array}{l}456 \\
302\end{array}$ & $\begin{array}{r}95.6 \\
145.5\end{array}$ \\
\hline
\end{tabular}

tion and the other five with each of the concentrations. The sites for injection of emulsions at each concentration were varied from one animal to another. The control injection of the stock solution (isotonic saline containing Aquet) was also made at sites similarly varied.

To determine the influence of tissue destruction and the osmotic effect produced by a chemical agent on the tissue water content, the actions of hydrochloric acid and of equimolar concentrations of sodium chloride were studied. From constant-boiling hydrochloric acid, solutions of $0.1,0.5,1.0,2.5$, and 5.0 per cent concentrations were prepared in distilled water. Equimolar concentrations of sodium chloride in distilled water were similarly prepared. Six sites were injected in each of six rabbits with the three lowest concentrations of hydrochloric acid solutions and the three osmotically equivalent solutions of sodium chloride. Equimolar solutions were injected in bilaterally symmetrical positions. In the same manner each of six rabbits was injected with 2.5 and 5.0 per cent hydrochloric acid solutions and the corresponding sodium chloride solutions.

\section{RESULTS}

All sites injected with Sovasol 35 and $360 \mathrm{E}$ appeared red and swollen, and a general trend of increased reaction with increased concentrations of irritant could be discerned. Control areas showed no evidence of inflammation. With one exception, $W$ values of the control areas ranged between 220 and 296. The $W$ values for areas injected with irritant were invariably greater than those of the corresponding control.

The control values of $W$ and the $W$ values ob-

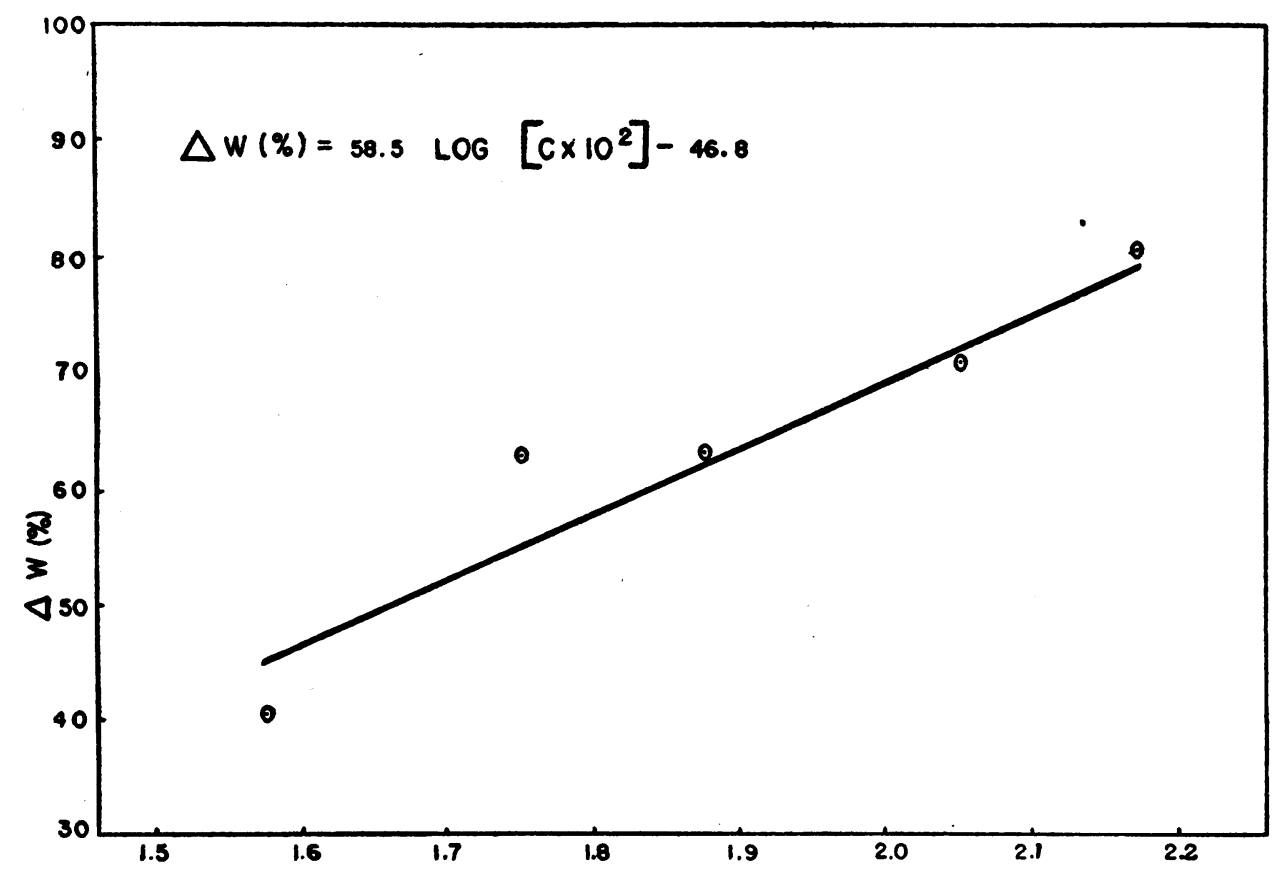

Fig. 1. Log [Concentration Sovasol 35 (grams) $\times 10^{2}$ ] 
TABLE II

Linear coefficients and statistical data

\begin{tabular}{l|c|c|c|c|c|c|c}
\hline \hline \multicolumn{1}{c|}{ Irritant } & a (intercept) & b (slope) & $\begin{array}{c}\text { Linear } \\
\text { regression }\end{array}$ & $\begin{array}{c}\text { Residual } \\
\text { regression }\end{array}$ & $\begin{array}{c}\text { Total } \\
\text { variability }\end{array}$ & F value & $\begin{array}{c}\text { Standard de- } \\
\text { viation from } \\
\text { regression } \\
\text { (per cent) }\end{array}$ \\
\hline Sovasol 35 & -46.8 & 58.5 & 778 & 85 & 863 & 27.5 & 4.7 \\
360E & -103.4 & 90.1 & 1,846 & 79 & 1,924 & 71.9 & 5.4 \\
Hydrochloric acid & -40.3 & 42.4 & 3,102 & 68 & 3,170 & 135.5 & 4.9 \\
\hline
\end{tabular}

tained at a particular concentration were subjected to regression analysis. Results indicated that a statistically significant relationship existed between the state of hydration of the essentially normal control sites and the response of the tissue to the chemical irritant. This relationship may be demonstrated by the two animals in the series in which the $W$ values were widely divergent (Table I). Expression of the results in per cent change in $W$ with respect to the control value indicates that the relative changes in $W$ with change in concentration are comparable when the influence of normal biological variations is considered. For this reason the criterion adopted in this study was the per cent change in $W$ rather than the absolute value of $W$.

The skin of animals injected with hydrochloric acid showed definite necrotic changes at sites injected with 5 per cent solutions. External evidence of inflammation was observed at sites injected with the three highest concentrations of hydrochloric acid. Areas injected with 0.1 and 0.5 per cent concentrations of hydrochloric acid did not exhibit any visually apparent signs of inflammation. The $W$ values of sites injected with hydrochloric acid were, however, appreciably greater than the values obtained for the corresponding control areas. The concentrations of sodium chloride employed did not produce significant changes in $W$.

The per cent change in $W$ with respect to the control site was computed. The mean of the change at each concentration was plotted against the logarithm of the concentration of irritant

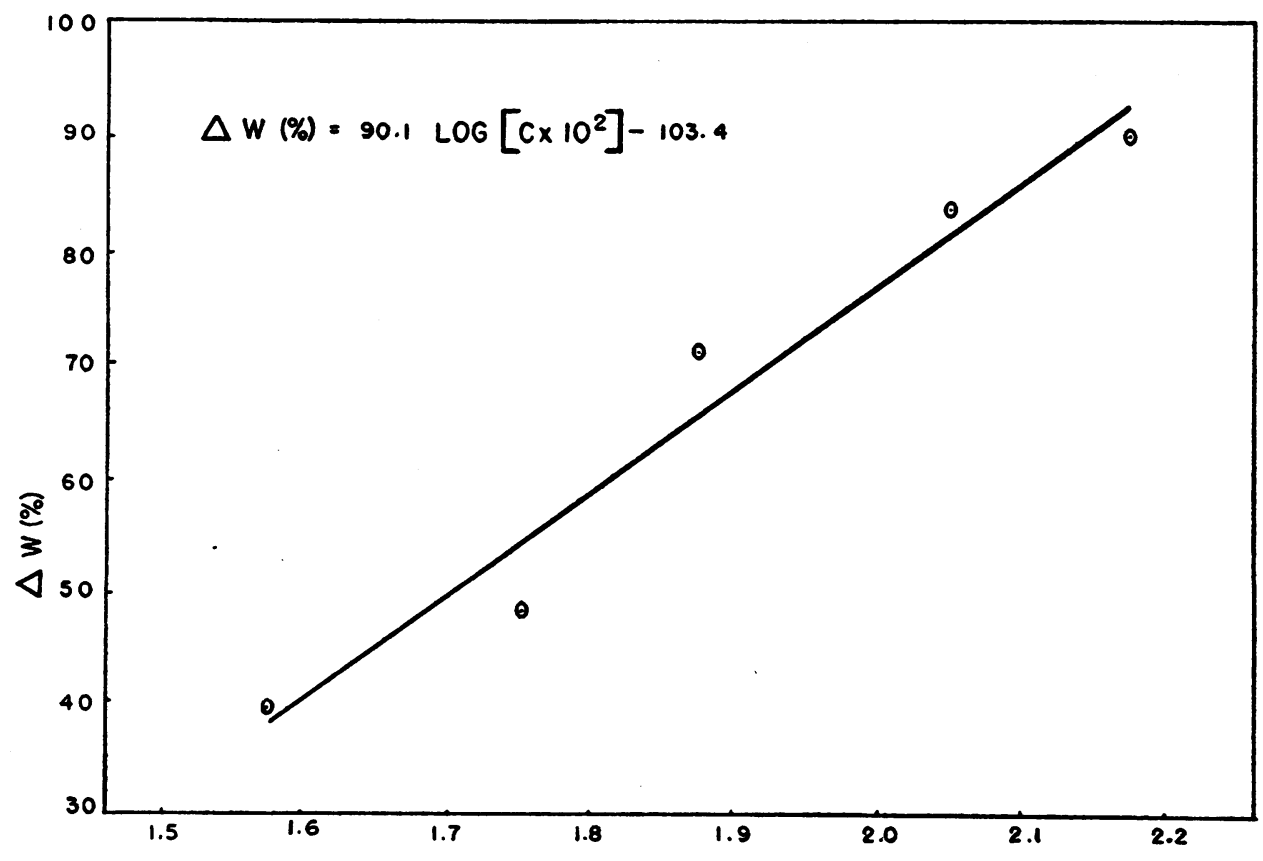

Fig. 2. Log [Concentration 360 E (Grams) $\times 10^{2}$ ] 


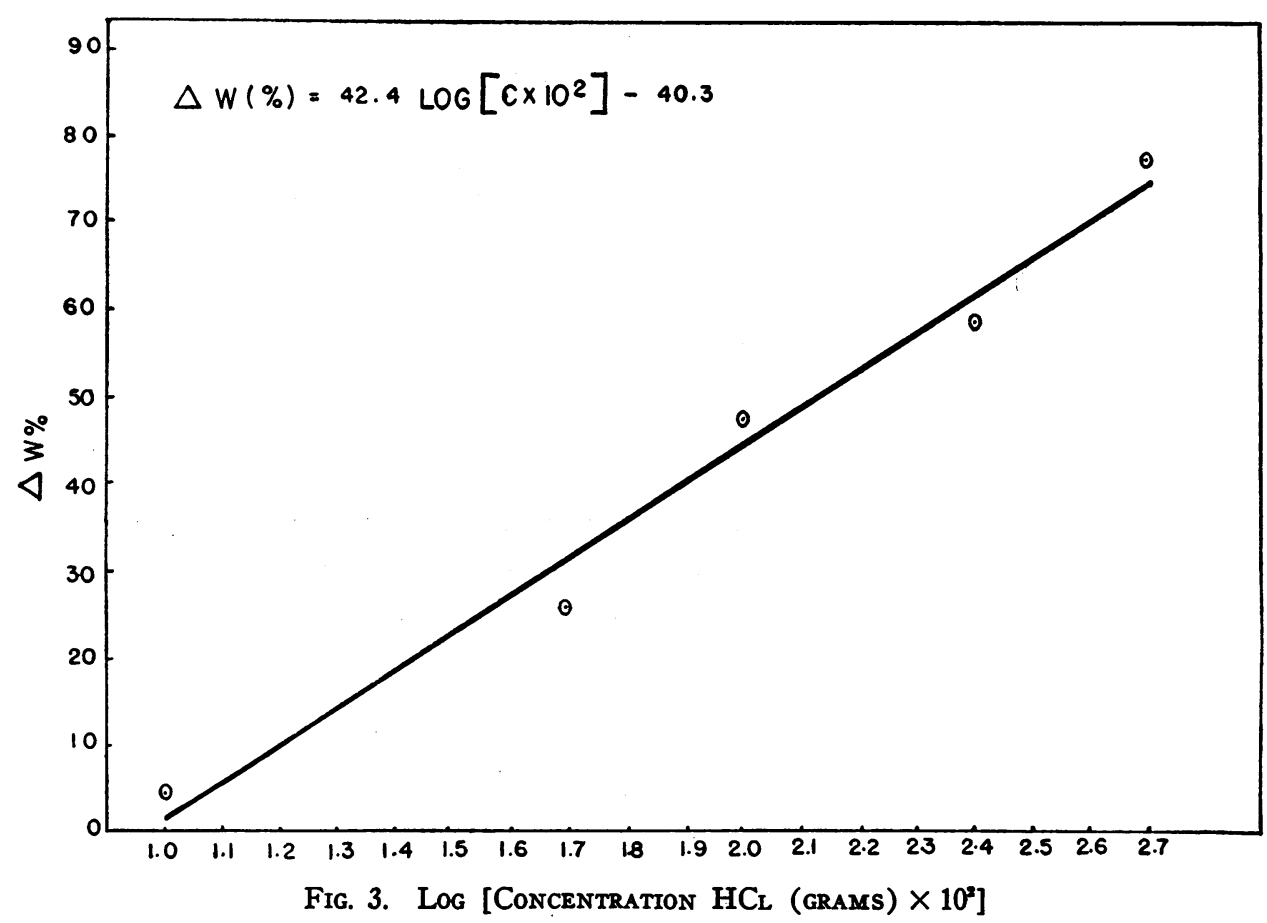

(grams) and a straight line relationship of the form :

$$
\Delta W(\%)=\mathrm{a}+\mathrm{b}(\log \mathrm{C})
$$

was obtained, where

$$
\begin{aligned}
\Delta W(\%)= & \text { per cent change in } W, \\
\mathrm{a}= & \text { a constant determined by the point } \\
& \quad \text { of intercept on } \Delta W(\%) \text { axis, } \\
\mathrm{b}= & \text { a constant determined by the slope } \\
& \quad \text { of the plotted line, } \\
\mathrm{C}= & \text { concentration of irritant. }
\end{aligned}
$$

By the method of least squares (4), the slope of the line and intercept was determined. To avoid the computation with negative logarithmic values, each concentration was multiplied by $10^{2}$. The data were subjected to linear regression analysis and the $F$ value was computed. These data are shown in Table II for the three irritants studied.

At the 95 per cent confidence level, the tabular value of $F$ is 10.13 (three degrees of freedom). The computed $F$ value for the lines of regression of the three irritants studied exceeded this value. These results indicate that a linear relationship of statistical significance exists between the change in water content of tissue and the logarithm of the concentration of irritant injected. The standard deviation from regression was approximately
5 per cent. The mean of six values at each concentration and the straight line derived by formulae from these data are shown in Figures 1, 2, and 3 for Sovasol 35, 360E, and hydrochloric acid, respectively.

\section{DISCUSSION}

A linear relationship of statistical significance between the logarithm of the concentration of irritant and the water content of injected sites has been demonstrated experimentally. These results correlate with the fundamental changes which occur in inflammatory reactions. The increase in water content of the experimentally induced inflammation by the chemical irritants may be regarded as an index of inflammation. The primary importance of this relationship is that it establishes a method for the evaluation of inflammation by a totally objective procedure. Further, the method should provide for comparisons of inflammation produced by different irritants over a range of concentrations.

As indicated, the response of tissue to an irritant depends upon its degree of hydration. Although the per cent change in $W$ was comparable, the sites of inflammation in rabbit 9930 appeared markedly more inflamed than the corresponding 
sites of rabbit 9931 (Table I). Attention is called to the fact that hydrochloric acid in low concentrations produces significant physiological changes, manifested by the increase in water content over that of controls, which are nevertheless unattended by visually apparent changes. For this reason the reliability of measuring inflammation by gross visual examination is questionable.

The study described was specifically designed to investigate the relation between chemically induced inflammation and the water content of tissue. Further investigation is indicated to determine whether a variety of compounds obey the formula $\Delta W(\%)=\mathrm{a}+\mathrm{b}(\log \mathrm{C})$. It would be of importance to determine also whether the concentration value obtained by extrapolation of the straight line to the abscissa (zero change in $W$ ) represents the concentration of irritant on the borderline of producing inflammation. If this be the case, an objectively determined numerical concentration value may be assigned to a chemical irritant and recorded in the literature as the minimal inflammatory concentration.

\section{SUMMARY}

The relation between water content of dermal tissue and inflammation produced by chemical irritants was investigated. A linear relationship of statistical significance was found to exist between the per cent change in water content and the logarithm of the concentration of irritant injected for three irritants studied. The change in water content in response to an irritant is regarded as an index of inflammation. These findings offer a potential method of quantitatively determining inflammation by a completely objective procedure.

\section{REFERENCES}

1. Munch, J. C., Manual of Biological Assaying. J. B. Lippincott Co., Philadelphia, 1937, p. 115.

2. Oettel, H., Einwirkung organischen Flüssigkeiten auf die Haut. Arch. f. exper. Path. u. Pharmakol., 1936, 183, 641.

3. Weatherby, J. H., A method for the quantitative estimation of chemical irritation. J. Lab. \& Clin. Med., 1940, 25, 1199.

4. Freeman, H. A., Industrial Statistics. John Wiley \& Sons, Inc., New York, 1942, p. 101. 